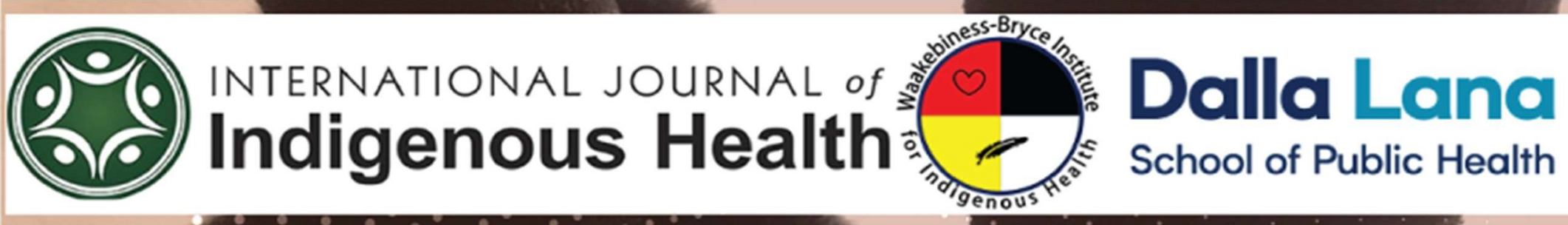

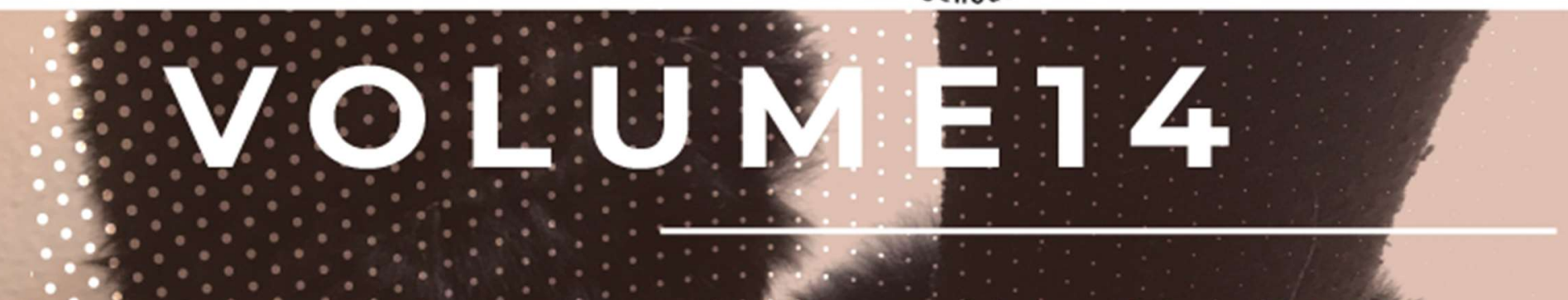
Issue N.1 May 2019

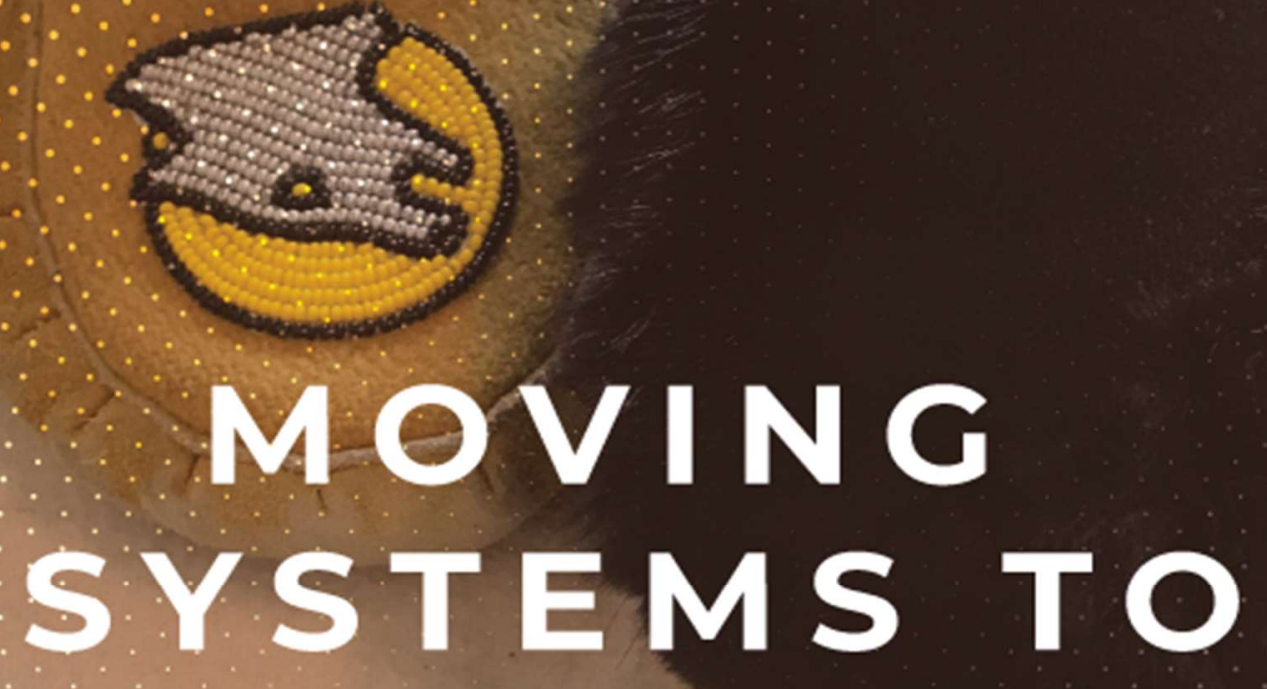

CULTURAL SAFETY 


\section{Cover Page Artwork:}

"A walking person, a route, a pathway in connection with nature and others."

Author: Juan Carlos Rodriguez, 2019.jc.rodriguez@utoronto.ca

Waakebiness-Bryce Institute for Indigenous Health 


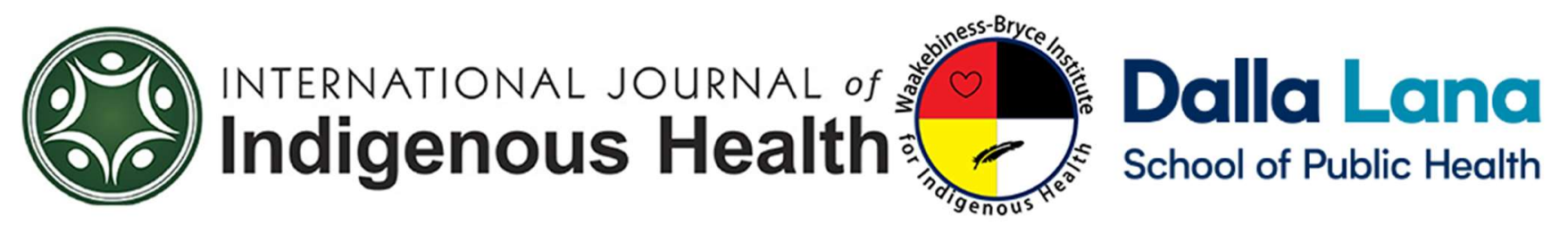

$3-7$

Articles

8- 28

29- 41

$42-59$

$60-84$

$85-106$

$107-125$
Editorial

Suzanne Stewart, Angela Mashford-Pringle. Waakebiness-Bryce Institute for Indigenous Health, Dalla Lana School of Public Health, University of Toronto.

Community-Specific Risk and Protective Factors for Risky Alcohol Consumption in American Indian Women of Reproductive Potential: Informing Interventions.

Annika C Montag, Dan J Calac, Christina D Chambers.

Evaluation of the Indigenous Relationship and Cultural Safety Courses among a sample of Indigenous Services Canada nurses.

Michelle Rand, Amanda Sheppard, Sehar Jamal, Angela Mashford-Pringle.

I'taamohkanoohsin (everyone comes together): (Re)connecting Indigenous people experiencing homelessness and substance misuse to Blackfoot ways of knowing. Janice Victor, Melissa Shouting, Chelsey DeGroot, Les Vonkeman, Mark Brave Rock, Roger Hunt.

Cultural Safety Training for Health Professionals Working with Indigenous Populations in Montreal, Quebec

Sean Yaphe, Faisca Richer, Carrie Martin.

A First Nation Framework for Emergency Planning: A Community-Based Response to the Health and Social Effects from a Flood.

Stephanie Montesanti, Wilfreda E. Thurston, David Turner, Reynold Medicine Traveller.

Building on Strengths: Collaborative Intergenerational Health Research with Urban First Nations and Métis Women and Girls.

Elizabeth J. Cooper, S. Michelle Driedger, Josée G. Lavoie. 


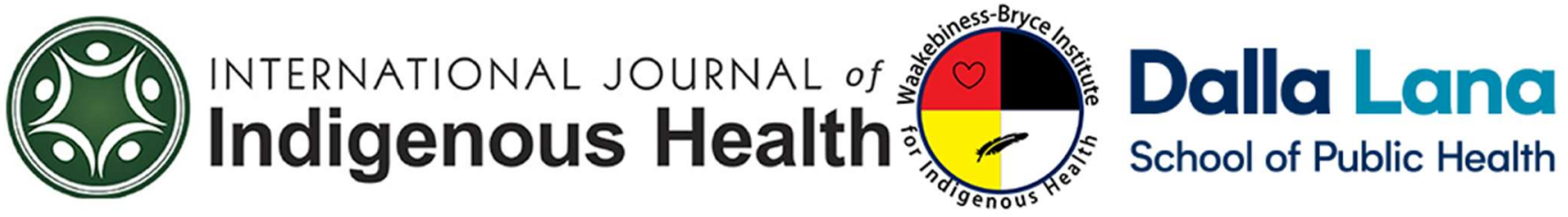

\section{Publisher}

Waakebiness-Bryce Institute for Indigenous Health

Research, Dalla Lana School of Public Health,

University of Toronto

\section{Editor}

Suzanne Stewart, Angela Mashford-Pringle

\section{Editorial Advisory Board}

Heather Castleden, Suzanne Christopher, Margo

Greenwood, Maura C. Hanrahan. Rod McCormick, Julianne Sanguins

\section{General Manager}

Juan Carlos Rodriguez

\section{Copy Editor}

Mikaela Gabriel

\section{Assistant}

Michael Auksi

\section{Cover Design and Layout}

Juan Carlos Rodriguez.

\section{Editorial Office}

International Journal of Indigenous Health,

Waakebiness-Bryce Institute for Indigenous Health, Dalla Lana School of Public Health,

University of Toronto, 155 College Street, Suite 40, Toronto, Ontario M5T 3M7

http://jps.library.utoronto.ca/index.php/ijih/index

ISSN 2291-9368 (Print) 2291-9376 (Online)

Volume 14, N1, DOI:10.32799/ijih.v4i1

\section{May 2019, Volume 14, Issue 1}

The International Journal of Indigenous Health is a peer-reviewed publication of the Waakebiness-

Bryce Institute for Indigenous Health at the Dalla Lana School of Public Health,

University of Toronto.

\section{Copyright/Permission to Reproduce: The}

International Journal of Indigenous Health has an exclusive license for the articles published herein, limited to first right of publication granted by the author(s) who hold copyright. The WaakebinessBryce Institute for Indigenous Health provides free, open access to the articles herein. Articles herein are covered by applicable copyright law and Creative Commons license granted to the International Journal of Indigenous Health by the author(s) that allows readers fully credited use and reproduction and prohibits any derivative or commercial use of the article(s) published in the International Journal of Indigenous Health.

\section{Disclaimer}

The International Journal of Indigenous Health is funded by the Waakebiness-Bryce Institute for Indigenous Health (WBIIH). Articles represent the views of the authors and do not necessarily reflect the views of WBIIH, the Dalla Lana School of Public Health, or the University of Toronto. WBIIH at the University of Toronto assumes no responsibility or liability for damages arising from any error or omission, or from the use of any information or advice, contained in this publication.

\section{Subscription}

The International Journal of Indigenous Health is distributed free of charge through its website, which is online and open-access. If you wish to receive an email with the Table of Contents of newly released publications, please sign-up at https://jps.library.utoronto.ca/index.php/ijih/user/reg ister

\section{Submissions}

The International Journal of Indigenous Health accepts article submissions on the topic of Indigenous health globally. All submissions should be submitted via online on the Journal website: https://ips.library.utoronto.ca/index.php/ijih/about /submissions 


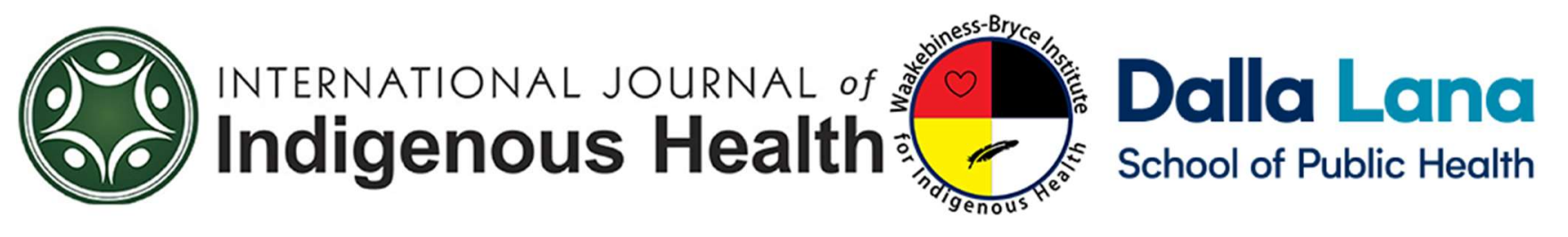

Volume 14

Issue 1. Physical Activity and Cultural Safety

DOI 10.32799/ijih.v14i1.32726

Editorial

May 2019

\section{Editorial}

\section{Moving and enhancing system change}

All Indigenous peoples across the globe have experienced multiple historical colonial aggression and assaults. In Canada and the USA for example, education was used as a tool of oppression for Indigenous peoples through residential school. Child welfare, health and health care, and forced land relocation are also sites of intensive and invasive harms.

Health services continue to be a site of systemic and personal oppression for Indigenous peoples across Canada and the world (Reading 2013). For many years, Indigenous peoples have faced discrimination and racism when accessing biomedical health care. Implementation of colonization in Canada, Australia, New Zealand, and elsewhere, have been well documented to adversely influence aspects of health in many Indigenous communities worldwide and linked to high rates of mental health, education, and employment challenges (see Loppie \& Wein, 2009; Mowbray, 2007; Paradies, Harris, \& Anderson, 2008); these traumas are rooted attempts in cultural extermination and deep-set pains in regard to identity and well-being (Stout \& Downey, 2006; Thurston \& Mashford-Pringle, 2015).

In Canada, the Indian Act (1876) outlawed Indigenous healing practices and traditional healers, traditional healing ceremonies, such as sweat lodge, smudging, potlatch, and more, and the use of traditional medicines. These systemic legislative changes to Indigenous peoples' lives effectively made illegal the practice of traditional health and wellness for Indigenous peoples and replaced them with ineffective and underused biomedical mental health service (Loppie \& Wein, 2009). Currently, healing and health promotion for Indigenous peoples who are surviving colonial traumas can begin through the reconnection and the relationship with current Indigenous traditional knowledge as well as through reducing experiences of personal and systemic racism and oppression within biomedical health care (Richmond, Ross, \& Bernier, 2007).

Research by Stewart (2016; 2017) and others (Allan \& Smylie, 2015; Smylie \& Anderson, 2006) has shown a generally poor Indigenous experience of health and mental health services, despite efforts 
to enhance cultural competency and culturally based service by Indigenous organizations and some biomedical community health centres and hospitals.

There has been an evolution of cultural care in Canada and worldwide. Despite well-meaning efforts to create cultural awareness and sensitivity, initially in the 1980s, among health care providers, little has been done to improve the health care system until Maori nurses in New Zealand introduced "cultural safety". Papps and Ramsden (1996) described cultural safety as having knowledge about the context and culture of people who are culturally different from the self in a way that acknowledges and addresses social and political power inequities toward a goal of self-determination for the patient and decolonization for the health care provider.

Cultural safety is defined by Papps and Ramsden (1996) as high-quality health care for individuals of diverse ethnicities in that it addresses value and identity difference, uses empathic listening and speaking, and holds health care providers to self-reflection in this process, and has an overarching goal of empowerment, advocacy, and collaboration.

Researchers and practitioners in health have suggested that employing a Western paradigm of both health and education with Indigenous peoples is a form of continued colonial oppression... and this continues to perpetuate intergenerational trauma (see Gone, 2004; Smylie, 2001; Stewart 2008). Cultural safety as both a framework and practice offer both health researchers and practitioners an alternative to colluding with a current colonial biomedical western system. As with any new framework, prescribed goals and processes will be required to measure and consider its success.

However, it is urgent that these new program and evaluations, like the practice of cultural safety itself, be based in Indigenous cultural values and knowledges and not biomedical western edicts, as all these have successfully proven is that all western biomedical programs and interventions have not worked with Indigenous peoples everywhere in the world. This issue shares articles about programs and research that strive towards this type of resistance to collusion and an adherence to practice grounded in Indigenous knowledges and cultural safety.

Miigwetch/Thank you,

Dr. Suzanne Stewart \& Dr. Angela Mashford-Pringle, Co-Editors 


\section{References}

Allan, B. \& Smylie, J. (2015). First Peoples, second class treatment: The role of racism in the health and well-being of Indigenous peoples in Canada. Toronto, ON: the Wellesley Institute.

Loppie Reading, C. \& Wien, F. (2009). Health Inequalities and Social Determinants of Aboriginal Peoples' Health. National Collaborating Centre for Aboriginal Health. Prince George, BC: National Collaborating Centre for Aboriginal Health.

Mowbray, M. (Ed.)(2007). Social determinants and Indigenous health: The International experience and its policy implications. Geneva, Switzerland: World Health Organization Commission on Social Determinants of Health.

Papps, E., \& Ramsden, I., (1996). Cultural Safety in Nursing: The New Zealand Experience. International Journal for Quality in Health Care, 8, 5, 491-497, https://doi.org/10.1093/intqhe/8.5.491

Paradies, Y., Harris, R. \& Anderson, I. (2008). The impact of racism on Indigenous health in Australia and Aotearoa: Towards a research agenda (Discussion Paper No. 4). Darwin, Australia: Cooperative Research Centre for Aboriginal Health.

Reading, C. (2013). Understanding Racism. Prince George, BC: National Collaborating Centre for Aboriginal Health.

Richmond, C., Ross, N.A., \& Bernier, J. (2007). Exploring Indigenous concepts of health: The dimensions of Métis and Inuit Health. In J. White, D. Beavon, S. Wingert, \& P. Maxim (eds). Aboriginal Policy Research: Directions and Outcomes Volume

Smylie, J. (2001). Building dialogue. Aboriginal health and family physicians. Canadian family physician Medecin de famille canadien, 47, 2444-2446, 2452-2445.

Smylie, J. \& Anderson, M. (2006). Understanding the health of Indigenous peoples in Canada: Key methodological and conceptual challenges. Canadian Medical Association Journal, 175(6), 602-602.

Stewart S. (2017). Supporting Indigenous youth experiencing homelessness in S. Kidd et al. (Eds.) Mental Health \& Addictions Interventions for Youth Experiencing Homelessness: Practical Strategies for Front-line Providers, 89-100. Canadian Observatory on Homelessness: York University.

Stewart, S. (2016). Mental health interventions for Aboriginal homelessness: Best practices from the street. Workshop presented at the Canadian Psychology Association Annual Convention, Victoria BC.

Stout, M. D., \& Downey, B. (2006). Nursing, Indigenous Peoples and Cultural Safety: So what? Now what? Contemporary nurse, 22(2), 327-332.

Thurston, J. M., \& Mashford-Pringle, A. (2015). Nursing \& Indigenous education integration. Journal of Nursing Education and Practice, 5(10). 
Follow the International Journal of Indigenous Health at:

https://jps.library.utoronto.ca/index.php/ijih/index

\section{Creative Commons Licence}

(C) $\Theta \Theta \Theta$

This work is licensed under a Creative Commons Attribution-Noncommercial-No

Derivative Works 4.0 License.

\section{Recommended Citation:}

Stewart, S., Mashford-Pringle, A. (2019). Editorial: Moving and Enhancing System Change. IJIH, 14(1), 3 - 7. DOI 10.32799/ijih.v14i1.32726. 